ence in the procedure, the number of perioperative complications has gradually decreased.

To conclude, endovascular treatment for aortobronchial fistulas is technically feasible and is associated with higher survival than conventional surgery. Midterm results in regard to cessation of hemoptysis episodes are good. Specific complications, such as endoleaks or the need for adjuvant processes, have not been eliminated yet. Stent improvement and optimal patient management will most likely decrease these complications inherent to the method. A longer term follow-up is required to establish the results of these procedures. Prospective, randomized studies allowing for an analysis of the results and a comparison with the results of conventional surgery are difficult to conduct because of the low prevalence of the condition and the urgent solution required.

\section{References}

1. Miyata T, Ohara N, Shigematsu H, Konishi T, Yamaguchi H, Kazama S, et al. Endovascular stent graft repair of aortopulmonary fistula. $J$ Vasc Surg. 1999;29:557-60.

2. Leobon B, Roux D, Mugniot A, Rousseau H, Cérene A, Glock Y, et al. Endovascular treatment of thoracic aortic fistulas. Ann Thorac Surg. 2002;74:247-9.

3. Thompson CS, Ramaiah VG, Rodriguez-Lopez JA, Vranic M, Rajogopalan R, DiMugno L, et al. Endoluminal stent graft repair of aortobronchial fistulas. J Vasc Surg. 2002;35:387-91.

4. Neuhauser B, Perkmann R, Greiner A, Steingruber I, Tauscher T, Jaschke W, et al. Mid-term results after endovascular repair of the atherosclerotic descending thoracic aortic aneurysm. Eur J Vasc Endovasc Surg. 2004;28:146-53.

5. Orend KH, Scharrer-Pamler R, Kapfer X, Kotsis T, Görich J, SunderPlassmann L. Endovascular treatment in diseases of the descending thoracic aorta: 6-year results of a single center. J Vasc Surg. 2003;37: 91-9.

\title{
Monobloc aorto-mitral homograft or mechanical valve replacement: A new surgical option for extensive bivalvular endocarditis
}

\author{
J. F. Obadia, MD, PhD, ${ }^{a}$ R. Hénaine, MD, ${ }^{a}$ C. Bergerot, $M D,{ }^{b}$ I. Ginon, $M D,{ }^{b}$ P. Nataf, MD, ${ }^{c}$ N. Chavanis, $M D,{ }^{a}$ \\ J. Robin, MD, PhD, ${ }^{a}$ X. André-Fouët, MD, ${ }^{\text {b }}$ J. Ninet, MD, and O. Raisky, MD, PhD, ${ }^{a}$ Lyon and Saint Denis, France
}

A ortic and mitral prosthetic valve endocarditis with extensive abscess is generally considered to be a critical situation with no satisfactory technical solution. ${ }^{1,2}$ Although we respect the principle of wide resection proposed by Tirone David, ${ }^{3}$ we report a simplified reconstruction solution using an aorto-mitral monobloc.

\section{Technique}

The first step consists of wide resection including the aortic and mitral valve prostheses, the proximal aorta, and the aorto-mitral curtain. This resection leaves a single gaping aorto-mitral orifice and 2 button-shaped coronary ostia. The second step of reconstruction can be simplified, when it is planned, using either a monobloc aorto-mitral homograft (Figure 1), for which we have already

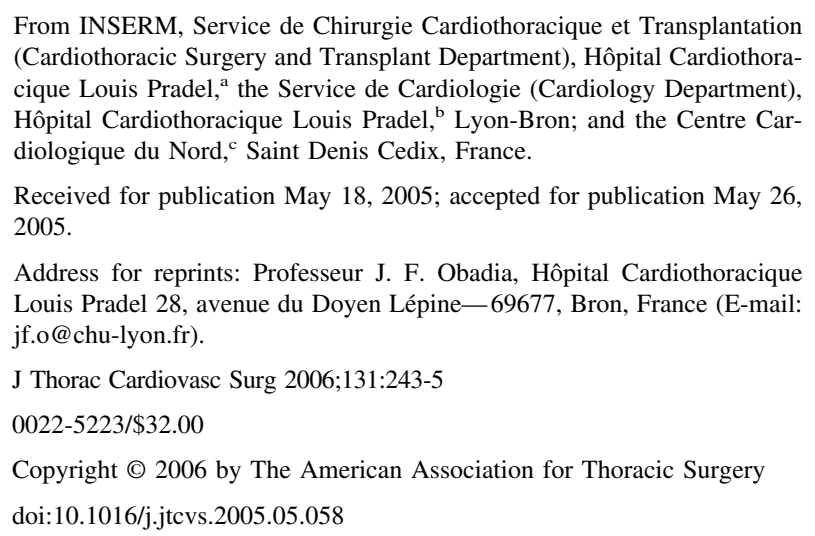

described the implantation technique, ${ }^{4}$ or a monobloc mechanical prosthesis prepared before starting cardiopulmonary bypass to limit the duration of the crossclamp time (Figure 2).

In both cases, an additional pericardial patch is necessary to reconstruct the roof of the left atrium, and the coronary ostia are reimplanted according to Bentall's technique.

\section{Patients}

Five patients aged 36 to 56 years underwent reoperation for the third to fifth time with extensive abscessing infectious endocarditis on aortic and mitral prostheses. One patient also had tricuspid extension with a ventricular septal defect. All 5 patients had severely altered hemodynamics and sepsis, and 3 of them were considered to be inoperable in another center before being referred to us. The microorganism isolated was Staphylococcus aureus in 2 cases, Candida glabrata in 1 case, Kingella dentrificans in 1 case, and Streptococcus sanguis in 1 case. The ejection fraction was always preserved $(>60 \%)$.

\section{Results}

Because of the availability of homografts in our tissue bank, 3 patients received an aorto-mitral homograft and the other 2 patients had to be treated by monobloc mechanical reconstruction. One patient also required placement of a tricuspid bioprosthesis and repair of an interventricular septal defect (mean crossclamp time: 186 minutes, mean cardiopulmonary bypass time: $231 \mathrm{~min}$ utes). All 5 patients recovered from the episode of endocarditis requiring surgery with satisfactory long-term echocardiographic follow-up of the reconstruction. However, 1 patient who was comatose on arrival in the operating room never recovered after 


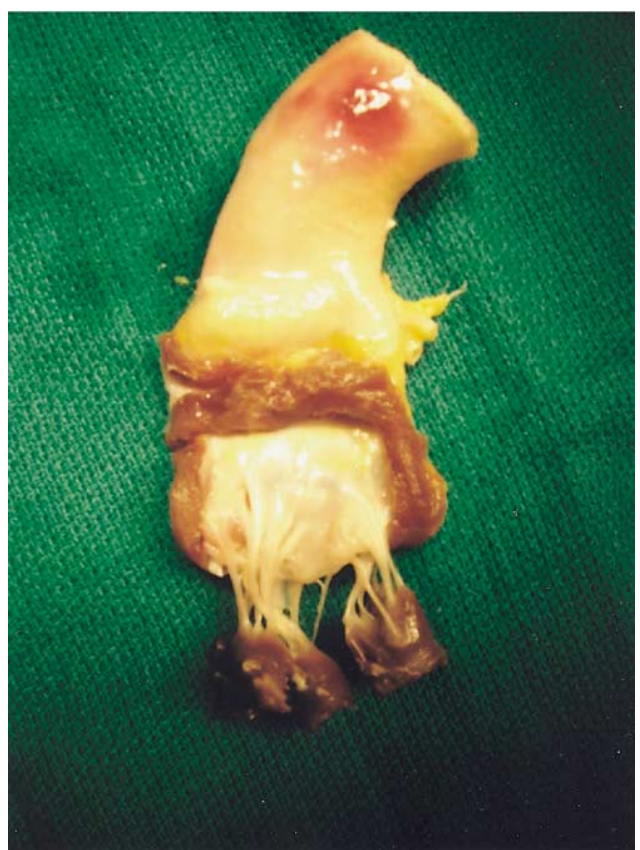

Figure 1. Monobloc aorto-mitral homograft. All hearts harvested for our tissue bank are dissected so the homograft includes the aortic valve and mitral valve in a single monobloc. When the surgeon thaws the monobloc, he or she can continue dissection to obtain an aortic valve, a mitral valve, or a bivalvular monobloc as necessary.

surgery and died of neurologic complications 6 months after the operation. Another patient died of progression of pulmonary abscesses 4 months after the operation. One patient completely recovered from an episode of infectious endocarditis (apyrexia for $>1$ year without antibiotics) but died suddenly after a follow-up of 18 months. The diagnosis of new infectious endocarditis was confirmed by the presence of vegetations and rupture of the posterior papillary muscle insertion of the homograft. Two patients (1 with a homograft and 1 with monobloc mechanical valve replacement) are still alive with a follow-up of 5.5 years and 2 years, respectively. Totally afebrile mitral regurgitation developed in the patient with a homograft after 21 months, requiring reoperation for mitral valve replacement with a St Jude Medical prosthesis ( $\mathrm{St}$ Jude Medical Inc, St Paul, Minn). No infection was detected on intraoperative samples, and the patient remains asymptomatic 5.5 years after the episode of infectious endocarditis. Follow-up echocardiography of the remaining aortic homograft and the St Jude Medical mechanical prosthesis was perfectly satisfactory. One patient with a monobloc aorto-mitral prosthesis and tricuspid bioprosthesis is in satisfactory condition apart from right ventricular failure, which is well controlled by medical therapy.

\section{Discussion}

The 2 postoperative deaths and the secondary death were related to the severe general state of these patients. However, cure of the

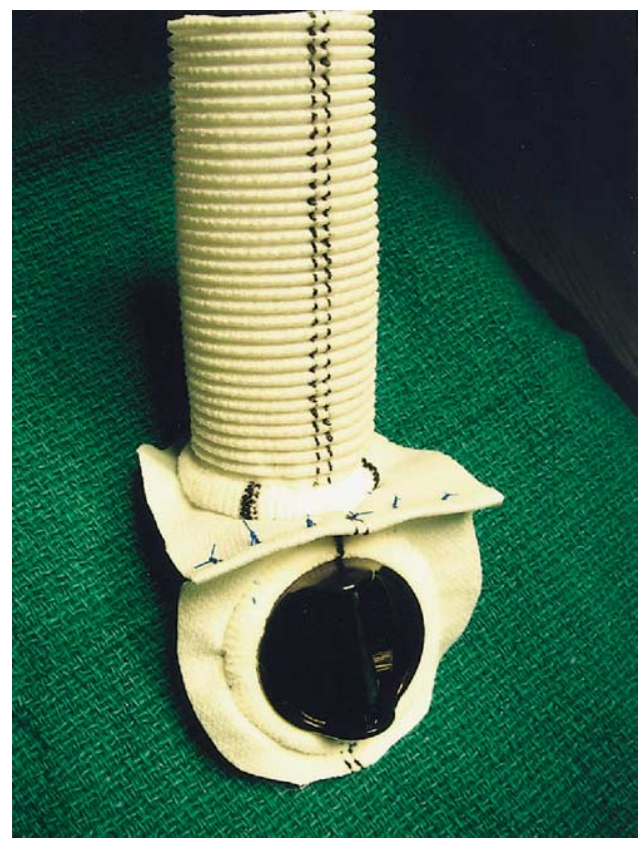

Figure 2. Monobloc aorto-mitral mechanical valve replacement. A St Jude Medical mitral valve prosthesis and a St Jude Medical tubular aortic valve prosthesis (St Jude Medical Inc, St Paul, Minn) were implanted on a sheet of Dacron. A fold in the Dacron was created by interrupted sutures to allow implantation of an additional patch to reconstruct the roof of the left atrium. The dimensions of the prostheses can be determined preoperatively on the basis of the dimensions of the patient's infected prostheses, and the orifice left by resection is always sufficiently large and flexible to receive an adapted monobloc prosthesis.

valvular septic process in 5 patients confirms the relevance of an oncologic surgical technique comprising inevitably destructive wide resection, followed by reconstruction, which can be long and difficult. Tirone David and colleagues ${ }^{5}$ proposed progressive reconstruction with successive insertion of a mitral valve prosthesis followed by an aorto-mitral pericardial patch, an aortic valve prosthesis, and finally another pericardial patch on the roof of the right atrium. We propose a monobloc reconstruction technique that is both simpler and more rapid provided this reconstruction is planned preoperatively. The monobloc aorto-mitral homograft can be dissected to obtain an aortic homograft comprising variable degrees of the mitral valve depending on the particular circumstances. When an aorto-mitral homograft is not available, construction of a monobloc mechanical valve before starting cardiopulmonary bypass enables a reduction of the clamping time. This technique is indicated in patients initially considered to be in critical condition, whose prognosis depends more on the general state than on the local lesions, which corroborates the analogy with cancer surgery. Of the 2 patients still alive today, 1 received a homograft and 1 received a mechanical valve, which suggests that the concept of extended resection may be more important than the 
nature of the substitute used for repair. These results should be confirmed in a larger population with a longer follow-up.

\section{References}

1. Haydock D, Barratt-Boyes B, Macedo T, Kirklin JW, Blackstone E. Aortic valve replacement for active infectious endocarditis in 108 patients. A comparison of freehand allograft valves with mechanical prostheses and bioprostheses. J Thorac Cardiovasc Surg. 1992;103: $130-9$.
2. Pulpon LA, Crespo MG, Sobrino M, et al. Recalcitrant endocarditis successfully treated by heart transplantation. Am Heart J. 1994; 127(4 Pt 1):958-60.

3. David TE. The surgical treatment of patients with prosthetic valve endocarditis. Semin Thorac Cardiovasc Surg. 1995;7:47-53.

4. Obadia JF, Raisky O, Sebbag L, Chocron S, Saroul C, Chassignolle JF. Monobloc aorto-mitral homograft as a treatment of complex cases of endocarditis. J Thorac Cardiovasc Surg. 2001;121:584-6.

5. David TE, Feindel CM, Armstrong S, Sun Z. Reconstruction of the mitral anulus. J Thorac Cardiovasc Surg. 1995;110:1323-32.

\section{Origin of left subclavian artery from ascending aorta: A variant of double aortic arch}

K. Mahadevan Krishnamoorthy, DM, DNB, Hemant Madan, MD, and Jaganmohan A. Tharakan, DM, Trivandrum, India
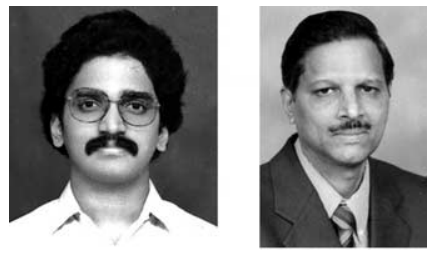

Krishnamoorthy (left) and Tharakan

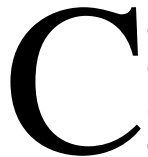

ongenital anomalies of aortic arch include abnormalities of branching or position and supernumerary or interrupted arch. An embryologic explanation is provided for a hith-

erto unreported association of the origin of left subclavian artery (LSCA) from the ascending aorta (AA) in a patient with tetralogy of Fallot (TOF) and right aortic arch.

\section{Clinical Summary}

A 1-year-old girl with TOF had normal peripheral pulses. Chest radiography showed a right aortic arch. She was catheterized to delineate coronary anatomy, which proved to be normal. In addition, a vessel was seen arising from the AA. Thus, an aortic root angiogram in frontal and lateral views was performed. A right aortic arch was seen. The LSCA was the first branch of the AA. Figure 1 shows the frontal view, and Figure 2 shows the lateral view. Subsequent branches of the aortic arch were the left common carotid, right common carotid, and right subclavian artery (RSCA), in that order.

\section{Discussion}

Right Arch With Anomalous Left Subclavian Artery. Mirror image branching is the most frequent form of arrangement of the arch vessels in right aortic arch; $98 \%$ have congenital heart disease. TOF is present in $48 \%$ of patients. Right aortic arch with anomalous LSCA

\footnotetext{
From the Sree Chitra Tirunal Institute for Medical Science and Technology, Trivandrum, India.

Received for publication August 22, 2003; revisions received February 23, 2004; accepted for publication March 2, 2004.

Address for reprints: K. M. Krishnamoorthy, DM, DNB, Sree Chitra Tirunal Institute for Medical Sciences and Technology, Trivandrum, India (E-mail: saikm@sctimst.ker.nic.in).

J Thorac Cardiovasc Surg 2006;131:245-7

$0022-5223 / \$ 32.00$

Copyright (C) 2006 by The American Association for Thoracic Surgery doi:10.1016/j.jtcvs.2004.03.059
}

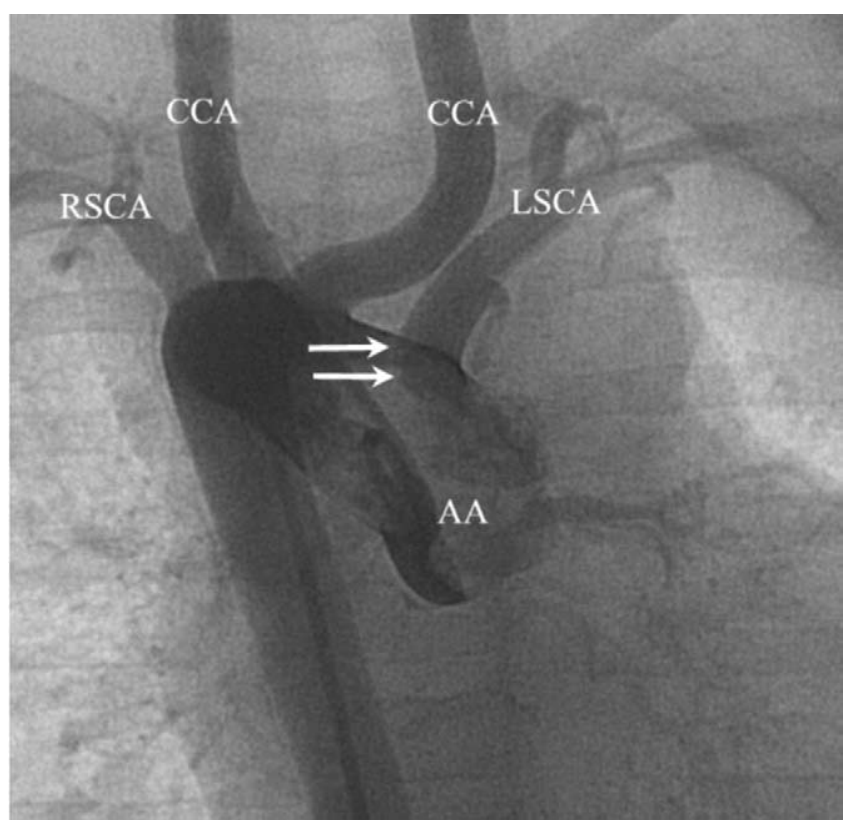

Figure 1. Aortic root angiogram; frontal view. $A A$, Ascending aorta; $L S C A$, left subclavian artery; $R S C A$, right subclavian artery; $C C A$, common carotid artery. Outline of the origin of LSCA (white arrows).

is described with the following sequence of branches: left common carotid, right common carotid, and LSCA. LSCA is the fourth branch and arises from the upper descending aorta. This has a lower incidence than a right arch with mirror image branching. ${ }^{1}$ In a study of anomalous SCA in TOF with a right arch, all of the 16 patients had anomalous LSCA arising from the distal portion of the right arch without the formation of a diverticulum. ${ }^{2}$ Origin from the AA has not been described. 